\title{
The Relationship Between Gestural Communication, Self - Efficacy, Preschool Progress and Gender Differences
}

\author{
Drd. Mihaela Buzatu \\ Faculty of Science Education and Informatics, Ion Creanga State Pedagogical University, \\ Chisinau, Republica Moldova
}

\begin{abstract}
The paper presents the resultsof a pilot study conducted on a sample of 161 preschoolers of ages 4 to 6 years old, in which 79 boys, 82 girls and 8 preschool teachers. The aim of the research was to establish the relationship between the self-efficacy, gestural communication and the preschooler progress.
\end{abstract}

Keywords: communication, preschool teachers, preschoolers, self-efficacy, preschool progress

DOI: $10.7176 / \mathrm{JEP} / 11-35-05$

Publication date: December $31^{\text {st }} 2020$

\section{Introduction}

Etymological meaning of communication is derived from the Latin word communico,-are, -avi, -atum = to make common, to sharing of something (information, knowledge, meanings) [6, p. 89].

The autorithies of communication domain[4,7,10,14,15] define the concept of communication like a complex terms. The communication involve four elements: the source, the message, the circumstance and the receiver and it involve any interaction or exchange, between two or more persons, of verbal, tactile, mimetic, gestural or digital communication messages.EzeukwuG.E.[apud10].

Wether someone wants to or not, the activity or inactivity, speech or silent, it inform about the inssur's status. According to the communication code we distinguish between verbal, nonverbal and paraverbal communication. The verbal communication is about language, both written and spoken. The nonverbal communication facilitates the verbal communinication, it's expressed through a variety of signs such as eye contact, facial expressions, gestures, postureand the distance between source and receiver. Paraverbal communication has as support the verbal communication. It customizes the utterance or writing of words by inflection, pacing, pitch, and tone of speech; by emphasis one places on particular words, phrases, or pauses while speaking. [5, pp. 395-396]

The pedagogical communication represents an axiomatic principle of educational activities which improve an educational message, prepared by source (teacher) which can determine the formative reaction of the education's object (the child/the student).[2, pp. 47-50]

The gestural language is an element of nonverbal language which make the act of communication more efficient. The gesture is understood as any bodily movement voluntary or involuntary carrying a communicative or affective meaning. [1].

In order to be able to translate the source's gesture, it's necessary to observe the other body movements too, simultaneously made with the analyzed gesture.

\subsection{Types of gestures in didactic communication}

- $\quad$ According to the function of the gesture[14] we differentiate between:

-emblems ,,are those nonverbalacts which have a direct verbal translation, or dictionary definition, usually consisting of a word or two , or perhaps a phrase. This verbal definition or translation of the emblem is well known by all members of a group, class or culture.” Example: performance appraisal- „very good” (raising the thumb).

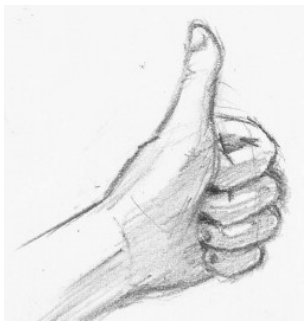

-ilustrators ,,are movements which are directly tied to speech, serving to illustrate what is being said verbally. " The teacher can describe with his / her hands the rhythm of action (fast, slow), the person (me, you), the spatial concepts (almost-far, up-down), the shapes (circle, triangle, square), the dimensions of the objects (big-small), the numbers etc. 


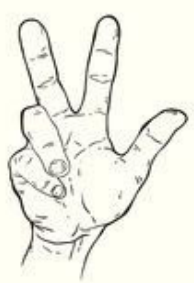

-regulators ,are acts to maintain and regulate the back-and-forth nature of speaking and listening between two or more interactants." The teacher manages to control the student's participation with the help of regulators who indicate who, when, how to participate. For example, the teacher can instruct the child to speak louder by bringing the hand to the ear.

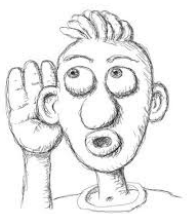

-adaptors „were first learned as part of adaptive efforts to satisfy self or bodily needs, or to perform bodily actions, or to manage emotions, or to develop or maintain prototypic interpersonal contacts, or to learn instrumental activities. In general, adapters are interpreted as signals of discomfort, nervousness, mental tension. (2, p. 130).

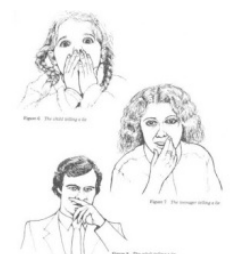

The teacher may notice a bored child kicking lightly, slipping on the chair; a child who wants to hide something that scratches his nose, he covers his mouth etc.

- $\quad$ According to the parameters of the gesture [6]:

Depending on the amplitude, can be distinguished wide gestures and restricted gestures. Wide and rounded movements correspond to positive feelings as opposed to restricted movements that most often have negative connotations.

Depending on the speed of execution, were identified alert gestures and slow gestures.

According to the direction of execution, there are centrifugal (outward) and centripetal (inward) gestures. Usually, outward-pointing hands express the communicator's communicative readiness, as opposed to systematically self-centered hands, which designate self-concern.

By precision, we notice precise gestures and imprecise gestures. Most often, precise gestures (e. g, touching a student to get his attention) are less prone to confusion than inaccurate gestures (e. g, clapping to catching the attention when a student whispering to a classmate). Sometimes inaccurate gestures have the advantage of a positive reaction from all students.

\subsection{Self-efficacy}

Albert Bandura use the self-efficacy term $[8,9,11,12,13]$ with meaning by "people which beliefs that they have the ability to exercise control over events that affect their lives" or "one's belief in being able to perform a specific task".

It's important not to confuse the self-efficacynotion with self-esteem. If self-esteem is general, self-efficacy refers to the subject's perception of a particular case. In the case of self-efficacy, unlike self-esteem, there is a possibility that the perception of one's ability to succeed may differ from one field to another (for example, someone may have a high level of self-efficacy in the artistic field, but a low level of self-efficacy in mathematics). [2, pp.182-186]

Regarding the relationship between self-efficacy and student learning motivation, Hadi Hassankhani [9, p. 4] found after a study that the connection between the two concepts proved to be positive and significant. Thus, the results showed that an increase in students' learning motivation could be associated with a higher level of perceived self-efficacy. 
2. Research on the relationship between gesture communication, preschool self-efficacy, preschool results and gender differences in preschool education

At the Faculty of Psychology and Education Sciences of the „Alexandru Ioan Cuza" University, from Iasi, Romania a pilot study realized by Buzatu Mihaela student, has been conducted during the academic year 20162017.

The aim of this research is to explore the relationship between school self-efficacy, students' sign language and preschool results.

This research involved 161 children aged 4-6 years, of which 79 boys and 82 girls, respectively 8 teachers in preschool education.

In conducting this research we combined the quantitative and qualitative approach. At the research's start, the children were recorded, with the consent of teachers and parents for about 15 minutes during the Language Development activities (Romanian language). Based on the video recordings, the children's gestures were quantitatively analyzed from the perspective of magnitude (number of large gestures and restricted gestures) and the direction of execution (number of centrifugal gestures and centripetal gestures). Wide gestures that extend beyond the body area and involve display in space of the extremities of the body, and restricted - gestures that do not exceed the body area. Also, were identified as centrifugal gestures those bodily movements performed outwards and as centripetal gestures the gestures performed towards oneself.

The children glued self-adhesive facial expressions (sad; very sad; happy; very happy;) on a questionnaire that included a scale for measuring preschool self-efficacy, adapted to the Self-efficacy Scale [11]. The scale contains 10 items related to the extent to which they manage to solve the learning tasck (for example: "Usually, when I have a problem in kindergarten, I can find a solution"). The children rated on a scale from 1 to 4 the disagreement, the partial disagreement, the partial agreement, respectively the total agreement with each statement. The items were read and explained to the respondents. For example, for the statement "I am confident that I can handle unexpected situations effectively", the term "effective" was explained to the students and an unexpected situation was exemplified (the presence of a foreign adult at the teaching activity).

Each professor participating to research provided the research organizer with a nominal table with the results of preschoolers in the Language and Communication Domain(LCD). The grades were used in the present research, respecting the confidentiality of preschoolers' personal data.

The quantitative analysis of data consisted in introducing in the SPSS system the variables: self-efficacy (with values from 1 to 4 depending on the students' answers), gender (female, male), gestures (centripetal, centrifugal, wide, restricted depending on the video recording result) and the results of LCD. For the gender variable, the $t$ test was performed, and the other variables were calculated using the Pearson correlation.

In qualitative analysis, the analysis technique used is the focus group. In compiling the focus-group guide, the research objectives were pursued (relationships between sign language, self-efficacy, gender and preschool results). The discussions were attended by 8 teachers with a seniority in the field between 1 and 41 years. The discussions of focus group were audio recorded, with the consent of the participants. Based on the recordings, a transcript was made that facilitated the thematic analysis of the content. The questions focused on the following topics:

1. The role of sign language in the educator-preschool relationship;

2. The relationship between gestures and the level of self-efficacy;

3. Correspondence between school results and students' self-efficacy;

4. The influences of sign language on preschool outcomes;

5. Gender differences in the level of self-efficacy;

6. Gender differences in sign language;

7. Gender differences in preschool outcomes.

During the research, was considered the verification of the following hypotheses:

1. There is a significant relationship between gestural communication in the didactic context and the level of peschooler's self-efficacy;

2. 1.a. Preschoolers with high self-efficacy will have a higher frequency of ample gestures;

3. 1.b. Preschoolers with high self-efficacy tend to show more frequent centrifugal gestures;

4. There is a significant relationship between self-efficacy and cognitive performance of preschoolers;

5. 2.a. Preschoolers who have a higher level of self-efficacy get better results to evaluation;

6. There is a significant relationship between the sign language shown by preschoolers and the evaluation results; 3.a. Preschoolers who predominantly execute ample gestures will get better results in assessment; 3.b. The preschoolers who show predominantly restrained gestures get bed results to assessment;

3.c The preschoolers who predominantly show centrifugal gestures will get better assessment results;

4. There are gender differences in preschool self-efficacy, sign language and assessment results;

4.a. The girls will have a higher level of preschool self-efficacy compared to the boys;

4.b. The girls will have a higher frequency of using gestural communication compared to the boys; 
4.c. The girls will perform better on assessment than the boys.

\section{The results of research}

Hypothesis 1:There is a significant relationship between gestural communication in the didactic context and the level of peschooler's self-efficacy;

1.a. Preschoolers with high self-efficacy will have a higher frequency of ample gestures;

The Pearson correlation indicates the existence of a modest but statistically significant positive relationship between the level of self-efficacy and the number of large gestures $(r=0.2, p=.01$, see Table 1)

1.b. Preschoolers with high self-efficacy tend to show more frequent centrifugal gestures;

The Pearson correlation coefficient shows a statistically significant positive relationship between the level of self-efficacy and the number of centrifugal gestures $(\mathrm{r}=.22, \mathrm{p}<.01$, see table 1$)$

Hypothesis 2: There is a significant relationship between self-efficacy and cognitive performance of preschoolers;

2.a. Preschoolers who have a higher level of self-efficacy get better results to evaluation;

The Pearson correlation coefficient showed a strong, statistically significant positive relationship between the level of self-efficacy and evaluation's results to $\operatorname{LCD}(\mathrm{r}=.5, \mathrm{p}=0$, see Table 1$)$

3. There is a significant relationship between the sign language shown by preschoolers and the evaluation results;

3.a. Preschoolers who predominantly execute ample gestures will get better results in assessment;

The Pearson correlation coefficient highlighted a statistically significant positive relationship between the performance of preschoolers to LCD and the number of large gestures $(r=.41, p=0$, see Table 1$)$.

3.b. The preschoolers who show predominantly restrained gestures get bed results to assessment;

Preschoolers' performance didn't correlate significantly with the number of restricted gestures.

3.c The preschoolers who predominantly show centrifugal gestures will get better assessment results;

The Pearson correlation coefficient showed a statistically significant positive relationship between the performances of preschoolers to LCDand the number of centrifugal gestures $(r=.42, p=0$, see Table 1$)$.

Tabelul 1

\section{Correlations}

$\mathrm{LCD}$

LCD

\section{Sig. (2-tailed)}

$\mathrm{N}$

Ample gestures

Sig. (2-tailed)

Restricted

gestures

Sig. (2-tailed)

centrifugal

gestures

Sig. (2-tailed)

$\mathrm{N}$

Centripetal

gestures

Sig. (2-tailed)

, 518

Self-efficacy

Sig. (2-tailed)

$\mathrm{N}$ gender

Sig. (2-tailed)

,001
Large gesture restricted

gestures
Pearson correlations between gender, type of gestures and self-efficacy

**. Correlation is significant at the 0.01 level (2-tailed). *. Correlation is significant at the 0.05 level (2-tailed)

*LCD-Language and Communication Domain 
Hypothesis 4. There are gender differences in preschool self-efficacy, sign language and assessment results; 4.a. The girls will have a higher level of preschool self-efficacy compared to the boys;

The $\mathrm{t}$ test for independent samples $(\mathrm{t}(158)=-2.6, \mathrm{p}=.01)$ indicated a statistically significant difference in terms of self-efficacy, by gender, in the sense that the girls obtained higher scores. (see Table 2) 4.b. The girls will have a higher frequency of using gestural communication compared to the boys;

The $\mathrm{t}$ test for independent samples $(\mathrm{t}(158)=-2.12, \mathrm{p}<.05, \mathrm{t}(156.31)=-2.42, \mathrm{p}<.05)$ indicated statistically significant differences in terms of ample gestures and centrifugal gestures, in the sense that girls expressed more gestures than boys (Table 2). Significant differences by gender weren't identified in terms of restricted and centripetal gestures.

4.c. The girls will perform better on assessment than the boys.

The $\mathrm{t}$ test for independent samples $(\mathrm{t}(158)=-3.67, \mathrm{p}=0)$ indicated statistically significant differences to the results of LCD in terms that the girls performed better than the boys (Table 2).

Tabelul 2 Gender differences in terms of preschoolers' performances, the gestures, the self-efficacy

Independent Samples Test

Levene's Test for Equality of Variances

\begin{tabular}{|l|l|l|l|l|l|l|l|}
$\mathrm{F}$ & Sig. & $\mathrm{t}$ & $\mathrm{df}$ & $\begin{array}{l}\text { Sig. (2- } \\
\text { tailed) }\end{array}$ & $\begin{array}{l}\text { Mean } \\
\text { Difference }\end{array}$ & $\begin{array}{l}\text { Std. Error } \\
\text { Difference }\end{array}$ & $\begin{array}{l}\text { 95\% Confidence } \\
\text { Interval of the } \\
\text { Difference }\end{array}$ \\
\hline
\end{tabular}

\begin{tabular}{|c|c|c|c|c|c|c|c|c|c|c|}
\hline Lower & & & & & & & & & & \\
\hline LCD & $\begin{array}{l}\text { Equal } \\
\text { variances } \\
\text { assumed }\end{array}$ & 1,000 & ,319 & $-3,679$ & 158 & ,000 &,- 45460 & 12356, &,- 69865 &,- 21055 \\
\hline
\end{tabular}

\begin{tabular}{|c|c|c|c|c|c|c|c|c|c|c|c|}
\hline $\begin{array}{l}\text { Equal v } \\
\text { not assur }\end{array}$ & & $-3,67$ & & 151,582 &, 000 & & 460 & , 12385 &,- 699 & & 992 \\
\hline $\begin{array}{l}\text { Ample } \\
\text { gestures }\end{array}$ & $\begin{array}{l}\text { Ec } \\
\text { va } \\
\text { ass }\end{array}$ & $\begin{array}{l}\text { ial } \\
\text { ances } \\
\text { med }\end{array}$ & 2,133 & , 146 & $-2,125$ & 158 & ,035 & $-2,07157$ & ,97466 & $-3,99661$ &,- 14654 \\
\hline
\end{tabular}

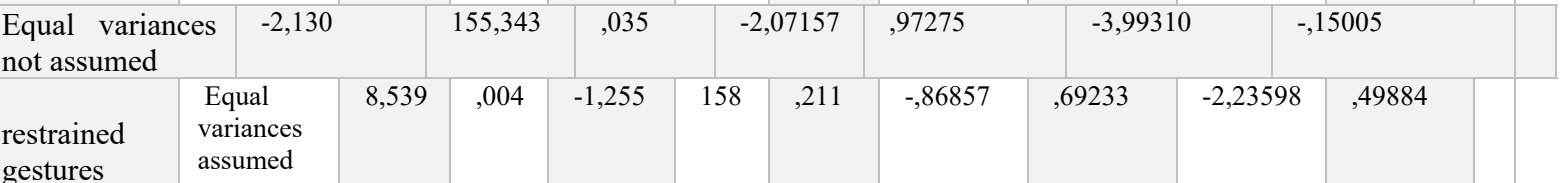

\begin{tabular}{|l|l|l|l|l|l|l|l|} 
Equal variances & $-1,260$ & 140,938 &, 210 &,- 86857 &, 68910 & $-2,23088$ &, 49373 \\
\hline
\end{tabular}

not assumed

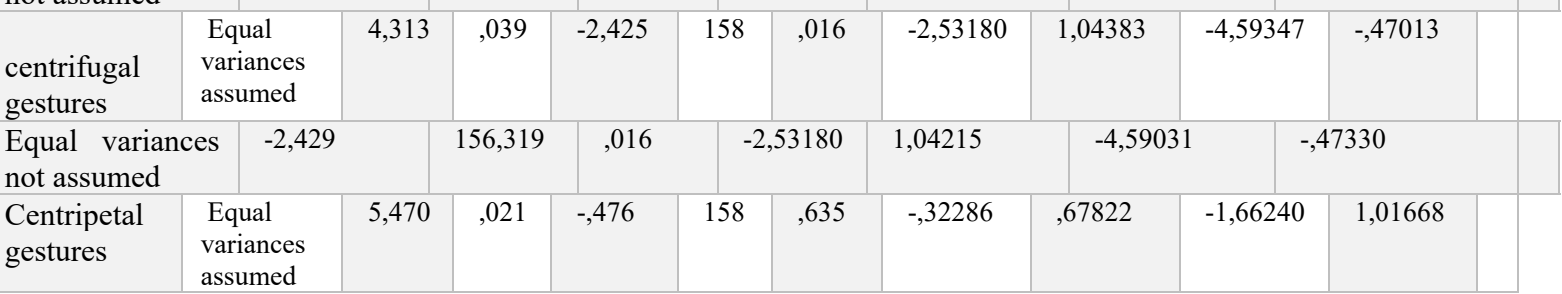

\section{*LCD- Language and Communication Domain}

\section{Conclusion}

The results of researchconfirms that preschoolers with high self-efficacy will have a higher frequency of ample gestures; preschoolers with high self-efficacy with a tendency to show more frequent centrifugal gestures; preschoolers with a higher level of self-efficacy prove higher cognitive performance; preschoolers who predominantly show ample gestures will get better preschool results; preschoolers who show predominantly centrifugal gestures will get better preschool results; girls will have a higher level of preschool self-efficacy compared to boys; girls will have a higher frequency of using gestural communication compared to boys; girls will have better preschool results than boys.

$3 \mathrm{~b}$ hypothesis according to which preschoolers who predominantly show restricted gestures obtain lower preschool results is not confirmed. So, we could conclude that restricted gestures are not necessarily a consequence of low cognitive performance but rather a consequence of his temperament, as indicated by most participants in the focus group.

The practical results implications of this research can be associated with the teachers training who insofar as they will show attention to the preschoolers'sign language, can contribute to improving the teaching-learning act.Therefore, communication competences of teachers are very necessary for teachersand preschoolers' success. 


\section{References}

Books:

1. Birkenbihl F., V.,(1999), Semnele corpului. Cum să înțelegem limbajul corpului. București: Editura Germana Press, 286

2. BURGOON, J. K., (1996), Nonverbal communication. New York: McGraw-Hill, 535

3. CHELCEA S., (2008), Comunicarea nonverbală: gesturile şi postura, București: Comunicare.ro, 299

4. COSMOVICI, A., Iacob L., (1999), Psihologie şcolară, Iași: Editura Polirom, 304

5. CRISTEA, S., (2000), Dicționar de pedagogie, București: Editura Litera, 400

6. CUCOȘ, C., (2006), Pedagogie, Iaşi: Editura Polirom, 641

7. CUCOŞ, C., (2009), Pedagogie pentru examenele de definitivare și grade didactice,Iași: Editura Polirom, 768

8. GUȚU GH., (1993), Dicționar latin-român. București: Editura Științifică, 472

9. MĂRGĂRITOIU, A., (2013), Gestul în comunicarea didactică,Iași: Editura Institutul Europen, 200

Articles

10. Bandura, A., (1991), Social Cognitive Theory of Self-Regulation. Organizatioal Behaviour and Human Decision Processess. 50, 248-287. [Online] Available http://www.uky.edu/ eushe2/BanduraPubs/Bandura1991OBHDP.pdf (October 25, 2017)

11. Hadi Hassankhani, Alireza Mohajjel Aghdam, Azad Rahmani, Zeynab Mohammadpoorfard, (2015), The Relationship between Learning Motivation and Self Efficacy among Nursing Students. Research and Development in Medical Education, 4(1), 97-101 doi:10.15171/rdme.2015.016 (online)

12. OKOLI, A. C. (2017), Relating Communication Competence to Teaching Effectiveness: Implication for Teacher Education. Journal of Education and Practice. 8 (3), https://files.eric.ed.gov/fulltext/EJ1131529.pdf

13. Schwarzer, R. (2007). The general self-efficacy scale. Health Psychology. [Online] Available http://userpage.fu-berlin.de/ health/ (October 25, 2017)

14. SHARMA, H. L., (2014), Academic self-efficacy: a reliable predictor of educational performances, in: British Journal of Education, vol.2, nr.3, 57-64. [Online] Available http://www.ea-journals.org/ (October 26, 2017)

15. VASILIU, D., Pascal -Marinescu, D. A, Marinescu G., (2014), Evaluarea autoeficacității. Proprietăți psihometrice pentru Self-efficacy scales: in Revista de studii psihologice, 2, 210-222. [Online] Available http://www.psiholog.danvasiliu.ro/ses.pdf (October 26, 2017)

16. Wagner Cook S., (2006), Goldin-Meadov S., The role of gesturein learning: Do children use their hands to change their minds?, Journal of cognition and development, 7, 211-212. https://doi.org/10.1207/s15327647jcd0702_4

17. ZIMMERMAN, J. B., Self-Efficacy: An Essential Motive to Learn, în Contemporary Educational Psychology Nr. 25, pp. 82-91. 2000 (IF: 2,863)

https://doi.org/10.1006/ceps.1999.1016

Sites:

18. https:/www.paulekman.com/wp-content/uploads/2013/07/Nonverbal-Behavior-And-Psychopathology.pdf (accessed October 27, 2020)

19. http://limbajultrupului.blogspot.com/2010/09/de-ce-copii-sunt-mai-usor-de-citit.html(accessed October $27, .2020)$

20. https://design.tutsplus.com/tutorials/human-anatomy-fundamentals-how-to-draw-hands--cms21440(accessed 27.10.2020)

21. https://www.deviantart.com/yonxi/art/HANDS-sketch-192482122(accessed October 27, 2020)

22. https://www.canstockphoto.com/hand-drawn-fingers-gesture-set-51954637.html(accessed October 2020)

23. http://popcristinaana.blogspot.com/2011/02/gesturile-de-baza-si-originea-lor.html(accessed October 27 2020) 